\title{
Uma vida em tradução: entrevista com John Milton
}

\section{Telma Franco Diniz}

Desde que chegou ao Brasil, no final dos anos setenta, após graduar-se em 'Letras: Literatura Inglesa e Espanhol', no Reino Unido, e depois de passar uma temporada na Espanha, o professor John Milton foi gradativamente construindo sua carreira na área de Tradução, ao mesmo tempo em que ajudava a erguer e consolidar a área de Estudos da Tradução no Brasil. Ao lado de sua atividade como tradutor de poesia, teatro, e ensaios acadêmicos, John fundou e é membro do conselho consultivo de muitas revistas de tradução no Brasil e no exterior; ajudou a fundar associações de tradutores; a criar grupos de estudos de tradução e de adaptação; a participar de bancas e orientar alunos em trabalhos sobre literatura inglesa e tradução; a organizar conferências na área; a acolher professores estrangeiros que vinham ao Brasil atendendo a seu convite para dar palestras ou cursos sobre tradução; a organizar antologias poéticas e a participar de outras tantas como tradutor; além de inúmeras outras atividades, que incluem constante participação no Bloomsday, em saraus de música e poesia, lançamentos de livros próprios e de terceiros, numa atuação semelhante à de um embaixador da tradução no Brasil. Essa trajetória teria culminado na criação do programa de pós em Estudos da Tradução da USP, o TRADUSP, do qual ele foi um dos idealizadores. Leitor voraz, John sempre leva consigo algum livro, desde que ficou ithado numa barraca de camping, olhos fixos na chuva interminável, numa viagem à França em 1972 - episódio recontado quarenta anos depois, no Memorial redigido para o concurso de Professor Titular na USP, em 2012. Poliglota - fala

\footnotetext{
* Doutora em Estudos da Tradução (USP/ 2018), com estágio no Centro de Estudos de Literatura Infantil [Children's Literature Research Centre] da Faculdade de Educação de Cambridge, Inglaterra. É mestre em Estudos da Tradução (UFSC/ 2012) e tem especialização em Tradução Literária (USP/ 2005). É tradutora autônoma inglês/português com experiência em legendagem, literatura infantil, poesia e literatura em geral, e textos publicitários e jornalísticos. Mediadora do Pensar Alto em Grupo, trabalha com poesia para crianças no Ensino Fundamental. Atua também com edição e revisão de textos, e com revisão de tradução. E-mail: telmafranco@ @otmail.com.
} 
francês, espanhol, português, alemão, italiano, um pouco de turco -, John já percorreu os 'quatro cantos do mundo', e passou a transformar as viagens em produção intelectual, unindo experiência pessoal a informações históricas, 'traduzindo', de maneira cativante e poética, os povos, culturas e lugares por onde passa. A experiência no Japão está eternizada em Imagens de um mundo trêmulo, traduzido para o português por Dirceu Villa e lançado pela Hedra, em 2006. Suas viagens pela Turquia e outros países do Oriente estão retratadas em palavras e imagens no livro Viagem à Turquia, Bálcãs e Egito, lançado também pela Hedra, em 2011, em tradução de Augusto Rodrigues.

Esta entrevista começou por email, entre os dias 12 e 25 de novembro, e se estendeu pela manhã de 27 de novembro, no mezanino da Biblioteca Mindlin, na USP, acompanhada por xícaras de café e imagens de intérpretes chineses e indígenas (apresentadas por ele em palestra recente). Em algumas das imagens, os intérpretes estão sendo submetidos a suplícios, talvez para confessarem uma suposta contravenção pelo uso indevido de informação privilegiada, ou talvez para confessarem a própria informação privilegiada, obtida durante o ofício, raramente isento de ossos.

Em 14 de janeiro de 2019, nosso entrevistado celebrará 40 anos de sua chegada ao Brasil, uma trajetória não isenta de ossos ou percalços, mas extremamente produtiva e frutífera, tanto em termos profissionais quanto pessoais. Pai do publicitário brasileiro Thomas, 37, que parece ter herdado a facilidade de fazer amigos, assim como a desenvoltura globe-trotter do pai (demonstradas em estadias na Inglaterra, Arábia Saudita, Espanha); e de Marcela, 7, herdeira dos olhos azuis e de uma genuína alegria de viver dentro d'água e ao ar livre, John exerce tantas atividades diferentes e sua vida desperta tanto interesse, que foi difícil resistir a fazer desta entrevista um relato de história de vida, e não pedir que ele discorresse sobre suas memórias de infância: o primeiro contato com as letras e histórias que o marcaram, o aprendizado da primeira língua estrangeira, a descoberta (ainda na infância) de que havia uma atividade que lhe permitiria entender algo dito em outra língua, e a que chamam tradução...

John: Na Birmingham dos anos 1950 e 1960 pouca gente viajava, não se escutava nenhuma língua estrangeira nas ruas, e os homens da minha família só tinham viajado para fora nas duas grandes guerras. Em Lakey Lane Primary School tivemos umas aulas de francês aos 10 e 11 anos, com a Mrs Beadle, e parecia que ela falava francês bem, mas acho que ela brigou com Mr Burgess, o headmaster, e as aulas de francês pararam. Me lembro de uma coisa que não entendi muito bem: como é que uma língua podia ter masculino e feminino. Hoje em dia é difícil imaginar quanto monolíngue era meu mundo. 
Aos 9 ou 10 anos assisti a uma versão dublada de Robinson Crusoe feito na Holanda. Tinha uma coisa esquisita na movimentação das bocas dos atores, mas não consegui sacar o que era. Adorava o Tintin, e de vez em quando aparecia uma tomada com palavras em francês, e claro que era mais fácil esconder a língua original em desenho animado. E nunca saquei que Tintin (pronunciado como o metal) não fosse inglesinho!

Aos 14 anos, já em King Edwards School, também em Birmingham, tivemos a possibilidade de escolher entre biologia, alemão e espanhol. 0 conselho era que quem se interessasse pelas ciências, tinha de fazer alemão, a língua das ciências naquela época. Então tomei umas dessas decisões que muda a vida de cada um, e escolhi o espanhol.

Telma: No seu Memorial E o sol se põe sobre Osasco, redigido para o concurso de Professor Titular na USP, você fala dos meses felizes que passou em Madri em 1977, quando a vida era uma constante festa, o que me fez lembrar dos versos "Yo vivía en un barrio de Madrid, con campanas, con relojes, con árboles... Mi casa era llamada la casa de las flores...", do Neruda. Você também conta que no ensino secundário leu autores como Calderón e Antonio Machado, o que nos faz pensar que seu contato com a língua e cultura espanholas foi mediado por boa literatura. Por outro lado, você diz que seu "relacionamento com o português nunca foi fácil por razões pessoais e por certo deslocamento". Será que no caso do português faltou a mediação de boa literatura? Gostaria de discorrer sobre isso?

John: Fiz um deslocamento para um país, Espanha, numa época maravilhosa, de setembro de 1976 a junho de 1977, com 20 anos, quando passei um ano do curso de Letras da Universidade do País de Gales em Madri. Franco tinha acabado de morrer em 20 de novembro de 1975, e o Rei Juan Carlos, designado por Franco como seu sucessor, apontou Adolfo Suárez como o primeiro ministro que ia orientar a mudança para o regime democrático. Foi uma época fantástica. A Espanha acordava em liberdade depois de uma repressão de 40 anos. As viúvas começavam a trocar suas roupas de luto; las chicas começaram a sair depois das 10 da noite; o Piso Chollo que eu dividia com um grupo de chicos españoles virava boate várias noites por semana; e o sexo foi (re)descoberto. Como nas palavras de Wordsworth: Bliss was it in that dawn to be alive, but to be young was very heaven! Voltei para Swansea para terminar a graduação, visitando Madri nas férias para ver Heloisa e os outros amigos. Meu castelhano estava melhorando bastante. Tinha um entrosamento com o país. Adorava a vida e o fervilhamento das cidades. E o vinho era mais barato que a água! Era o lugar óbvio para continuar minha 
vida, pelo menos por alguns anos. Mas não. Heloisa tinha de voltar ao Brasil. Talvez pudesse ter prorrogado sua estada na Espanha, mas dois anos longe da família era o suficiente e depois de ficar seis meses na Inglaterra, eu tinha de ir junto com ela ao Brasil...

Eu sentia muitas saudades, não de Birmingham ou da Inglaterra, mas de Madri e da vida que tinha e deixara para trás, para entrar numa família que parecia ter saído de uma peça de Nelson Rodrigues, numa cidade que julgava feia, nas cinzas do fim da ditadura, de poucas atrações, onde faltava aquela vivacidade de rua que encontrava em Madri. Um deslocamento grande na vida é bastante; fazer dois grandes deslocamentos num espaço curto de tempo é demasiado.

Entrei no português pelo castelhano; nas férias em 1977-78 fiquei uma semana no apartamento que Heloisa dividia com amigas brasileiras. Aprendi palavras como fofinho e beijoqueiro, e aprendi também que nunca podia dizer Estou cheio, sempre tinha de usar Estou satisfeito. Nunca tive nenhuma aula formal de português. No Brasil tinha medo de perder meu castelhano. Só comecei a me sentir razoavelmente cômodo para escrever em português depois de muitos anos aqui.

Telma: Você faz muitas coisas ao mesmo tempo, atua em vários campos, e muitas pessoas te consideram um agregador. Você vê alguma conexão entre seu interesse pelo Outro e seu interesse pela Tradução?

John: Talvez isso seja uma das coisas que consegui fazer: juntar as pessoas, começar comunidades, apresentar pessoas que têm interesses semelhantes, distribuir informações, descer da torre de marfim. Fico muito orgulhoso do grupo GREAT, o Grupo de Estudos de Adaptação, que começou como resultado de minha disciplina em Adaptação, em 2014, por iniciativa dos alunos dessa disciplina. O grupo já organizou duas JOTAs (Jornada de Tradução e Adaptação) e se encontra uma vez por mês às sextas-feiras.

O envolvimento com a comunidade (nesse caso, acadêmica) é muito importante para mim. Recentemente estive na Alemanha, e tive pouco contato com o mundo acadêmico. Voltei ao Brasil para imediatamente ir para a Unicamp, para participar da VII Jornada de Estudos Shakespereanos, um evento que comecei a organizar no começo do milênio. Embora hoje em dia se esteja sempre em contato com sua comunidade eletronicamente, não é exatamente a mesma coisa. Depois da falta de contato na Alemanha, estava de novo entre amigos. Essa saudade da comunidade foi exatamente a mesma sensação que senti em estadias na Universidade de Leuven, de 2002 a 2003, e na Universidade de Tóquio, em 2005. 
Por outro lado, uma das coisas que eu não consegui fazer foi começar um Grupo de Estudos de Historiografia da Tradução no Brasil. Como se faz isso? Muitos professores, não só aqui na USP, mas em universidades do mundo inteiro, têm certo projeto, e só acolhem alunos que vão se encaixar nesse projeto. Eu acho que eu devia ter feito isso. Devia ter convidado alunos bons, e ter dito que havia vagas para quem quisesse entrar em tal projeto.

Eu nunca consegui esse grande projeto FAPESP. Houve pelo menos duas vezes em que projetos internacionais avançaram, mas não conseguiram apoio na última barreira na FAPESP. Então uma das coisas, talvez, se eu estivesse começando agora, seria tentar um projeto abrangente sobre Historiografia da Tradução, envolvendo vários professores e alunos. Claro que muito seria em cima do meu trabalho, mas poderia ter dado certo. Até posso falar outras coisas que eu deveria ter feito [risos].

Eu faço muitas coisas, talvez até demais. Eu devia ter me concentrado em certas coisas, e talvez devesse ter copiado os professores das ciências exatas, que são mais focados. Acho que uma das várias autocríticas é que eu venho fazendo múltiplas coisas, sem, às vezes, um certo tipo de foco. E claro, acontece muito no meio universitário: você acaba trabalhando mais na parte burocrática em certo momento da carreira. O que aconteceu comigo com o Tradusp acontece com muita gente. Quem quer subir para professor titular tem de fazer isso. Existem pesquisadores excelentes, posso dar o exemplo de Marcos Bagno, que é reconhecido internacionalmente, e escreve livros importantíssimos. Ele é uma figura controversa, mas, em termos de produção acadêmica, é excelente. Só que ele nunca vai ser professor titular, porque não se envolve com a parte burocrática, e também não sai em busca de apoio em agências de fomento. Ele nem trabalha no programa de pós-graduação da UnB. Não sei se brigou com muita gente de lá, mas foi convidado para trabalhar num plano de pós na UFF. Então parece que nas universidades, em muitas partes do mundo, as qualidades de gerenciamento é que são mais valorizadas. Assim, para subir na carreira, é preciso ser a jack of all trades (and a master of none). Em certas áreas da USP, e certamente na UNESP e na UnB, a pontuação para professor titular é assim. Só quem já levantou fundos com agentes pode entrar, para pedir verba. Então é interessante ver como a carreira acadêmica está indo! Se você pensa que sendo professor universitário você vai ter uma vida excelente, e vai ser pago para ler livros... [risos] Não é tanto assim. Procure outra profissão. Só uma parte é ler livros. Boa parte é relacionamento político, e boa parte é gerenciamento de projetos, essa parte burocrática. Algo que eu tinha feito relativamente pouco, antes do Tradusp. Mas, na universidade moderna, se você quer ficar bem com seus colegas, pegue a posição burocrática.

Há muitos aspectos da carreira acadêmica, e muitos tipos de professores acadêmicos. Ainda temos os monges e freiras: os professores totalmente 
dedicados às suas vidas acadêmicas, que não têm nenhum tipo de interesse fora de suas aulas e pesquisa, que mantêm uma vida casta e devota, e que se retiram às suas celas junto com seus computadores todas as noites. Há muitos professores totalmente dedicados ao seu assunto de pesquisa e têm pouco interesse no mundo fora Shakespeare, Cervantes ou Racine. Há muita gente que usa a universidade como trampolim político. Basta ver os debates atuais. Há gente que quer poder. Há gente que adora/odeia dar aula e foge/se apega à pesquisa. Há muita gente que descobre outra carreira e se dedica ao máximo a esse interesse, a psicoanálise, por exemplo, para se aposentar o mais cedo possível, e se dedicar à nova carreira. Há colegas que odeiam tudo na USP e não aparecem mais após a aposentadoria; e há aqueles que só se aposentam na idade máxima, hoje em dia 75 anos, e depois ficam com um enorme oco em suas vidas.

Telma: Você contou no Memorial que passou por uma experiência ruim durante uma viagem muito chuvosa pela França, quando se viu sem livro nenhum para ler e, por causa disso, hoje você sempre carrega um livro aonde quer que vá. Que gênero você prefere ler? Gosta de ler livros em tradução?

John: Você menciona aquela experiência minha na França, com 16 anos, quando um livro de Nevil Shute era tudo que tínhamos para ler em duas semanas, e estava chovendo o tempo inteiro. Desde então sempre tenho uma pilha de livros, e dentro de minha pochete há uma miniedição do Evangelho de São João em alemão. Acho que peguei numa igreja na Alemanha. Não sou nada religioso, mas é bom para meu alemão, e se faltar livro... E agora minha preocupação é não ter óculos para a leitura, e sempre ando com vários pares...

É sempre mais fácil ler na lingua nativa. Assim, dos brasileiros, entre outras coisas, já li Machado de Assis em tradução para o inglês, e também Os sertões, de Euclides da Cunha. Mas acho que vou esperar a tradução da Alison Entrekin para ler Grande sertão: veredas [risos]

Telma: Nas viagens, você considera mais fascinante constatar as semelhanças entre as culturas, ou descobrir as diferenças? Há algum país que você ainda queira ver de perto?

John: Todos somos marcados pela infância. Meus pais viajavam muito pouco, uma semana na praia no verão, em lugar escolhido para gastar o 
mínimo possível, e nada mais. Sempre fiz o contrário do que meus pais aconselhavam, e eis uma das razões para meu Wanderlust. Sempre tento ir para países novos, e este é o primeiro ano em muitos que não visito um país onde não estive antes.

É difícil dizer se há um lugar que tenha me impressionado mais do que outros. Claro, as grandes cidades do mundo. Mas as cidades estão sempre mudando. $E$ eu mesmo. E meu relacionamento com as cidades sempre muda. Recentemente passei rapidamente por Bratislava. Não reconheci a cidade que visitei pela última vez uns 15 anos atrás. E 15 anos atrás não reconheci a cidade que visitei pela primeira vez em 1992. A mesma coisa com Budapeste, onde estive em junho, bem mais aconchegante e atraente do que as últimas vezes que visitei, e, claro, uma cidade no verão é muito diferente de uma cidade no inverno.

Eu gostaria de revisitar a Índia, Austrália e Nova Zelândia, Rússia, Finlândia, Romênia, os Países Bálticos. Tentei entrar na Venezuela e não consegui.

Telma: Na época em que você escrevia o Memorial, você também estava encarregado de organizar e enviar à Capes os dados dos professores da FFLCH que iriam participar do novo programa de pós em Estudos da Tradução, à época capitaneado por você e pelos professores João Azenha e Francis Aubert. Em certo momento do Memorial você diz: "talvez pela primeira vez na minha vida acadêmica me sinto dentro de uma equipe empenhada em fazer um projeto acadêmico funcionar"; no parágrafo seguinte, você continua: "parece que a Capes está um pouco mais flexível com docentes podendo trabalhar em dois, e até três programas. Tudo foi enviado à Capes ontem, e vamos ver..." O que se viu foi que o empenho deu certo: o programa foi aprovado com nota 4,0 e as aulas começaram em 2012. Tudo ia (ou parecia ir) muito bem, com grande procura por parte dos alunos e boa produção docente e discente. Repentinamente, a Capes abaixou a nota do programa, fadando-o à extinção. Por quê? O que deu errado, a seu ver?

John: Refletindo sobre a breve vida do Tradusp, fica claro que nunca devíamos ter tentado fazer um programa novo na primeira instância. Não concordo com a Capes quando critica o programa por ter menos de $60-70 \%$ de professores com dedicação exclusiva ${ }^{1}$, mas sim, concordo com outras críticas:

\footnotetext{
${ }^{1}$ Aberto em 2012 com nota 4,0, o Tradusp ainda não contava, em 2017, com 60\% de docentes com dedicação exclusiva (um dos pontos observados pela Capes ao avaliar programas de pós). Desconsiderando que a razão para isso era sua origem recente, a Capes abaixou a nota do Doutorado para 2,0, impedindo-o de receber novas matrículas, e fadando-o, em última instância, à extinção.
} 
havia uma sobreposição: os outros programas - Inglês, Francês, Alemão, Espanhol e Italiano - mantiveram suas áreas de concentração em Tradução, e às vezes o Tradusp até competia com essas áreas. Uma aluna minha foi aprovada em Italiano e no Tradusp e optou pelo Italiano por causa do coorientador.

Telma: Então você sugere que poderia ter havido um acordo entre os programas de inglês, francês, alemão..., para que teses e dissertações voltadas à tradução ficassem nos Estudos da Tradução, para não haver sobreposição?

John: Não, nunca houve essa discussão. Eu acho que a gente se precipitou e nunca ia dar certo. Os programas não iam abrir mão de uma área de concentração muito importante, como a tradução.

Numa situação ideal, o Programa novo devia ter aberto linhas novas de pesquisa: LIBRAS, Interpretação, Tradução Intermedial, Machine Translation, mas claro, não tivemos pessoal especializado nessas áreas, e a maior parte das dissertações e teses acabaram sendo bastante tradicionais: comparando várias traduções literárias da mesma obra.

Telma: Sim, seria muito interessante e benéfico que novas linhas de pesquisa tivessem sido abertas, mas a decisão da CAPES, abaixando a nota, não deu tempo ao programa...

John: Mas não tínhamos esse pessoal. Uma área em que houve um crescimento enorme no Brasil, a partir de 2000, foi a área de LIBRAS. Não sei se na Faculdade de Educação da USP tem LIBRAS², mas acho que a USP perdeu o bonde. Um dos professores de Libras na PGET (Pós-Graduação em Estudos da Tradução) de Santa Catarina foi nosso aluno de gradução, mestrado e doutorado: Tarcísio Leite, que agora é professor na UFSC. Mas aqui acho que nunca houve essa tentativa, nunca houve aquela pessoa para organizar tudo. LIBRAS é uma área muito importante na PGET. Então perdemos o bonde, e o tipo de estudo de tese e dissertação desenvolvido aqui na USP raramente

\footnotetext{
${ }^{2}$ A Faculdade de Educação da USP oferece a Disciplina LIBRAS (Língua Brasileira de Sinais) no $7^{\circ}$ semestre da graduação em Pedagogia. O Departamento de Linguística da FFLCH oferece o curso de LIBRAS na modalidade EaD na página: https://edisciplinas.usp.br/course/view.php?id=5603\&section=1
} 
entra nessas áreas novas. Muita gente entra no programa e assiste às palestras da disciplina 'Tópicos da Tradução', mas a grande maioria resolve comparar traduções de uma mesma obra ou fazer uma nova tradução de uma obra conhecida, uma coisa bastante convencional, dentro do que sempre se fez. Vejo poucas teses e dissertações tratando dessas áreas novas. É claro que depende do pessoal, dos docentes. Não tivemos esses docentes. E nunca houve a possibilidade de contratar professores novos. Reynaldo Pagura e Luciana Carvalho, que eram da PUC, entraram no programa, e poderiam, sim, trabalhar com Interpretação. Mas Reynaldo está nos Estados Unidos agora. Luciana, sim, entrou na USP recentemente, e no futuro haveria possibilidade de ela trabalhar nessa área.

Também perdemos o bonde quando a EACH (USP Zona Leste) abriu em 2005. Parece que professores novos, com projetos interessantes, conseguiram abrir novos departamentos. Infelizmente, meus grandes amigos e colegas, os professores João Azenha e Francis Aubert, não tinham muito interesse em se deslocar várias vezes por semana para Guarulhos, e eu estava emaranhado em várias brigas no departamento. Mas se tivéssemos atuado, pode-se imaginar uma Escola de Tradução e Interpretação ao lado do Aeroporto de Guarulhos.

Telma: Quer dizer que chegou a se cogitar a criação de um curso de tradução em 2005, que poderia ficar na USP Leste? Outros professores, além dos citados, foram sondados para assumir a criação desse Curso?

John: Isso da Zona Leste ninguém pensou na hora. Naquela época eu estava de mal de muita gente. Mas mesmo que eu tivesse feito um projeto, acho que dificilmente eu teria tido o apoio de Francis e João. Eles sempre pensaram que a lógica seria criar primeiro o curso de graduação na área de tradução, e depois ir para a pós-graduação. Mas nunca ia ter essa possibilidade de fazer graduação. Então Álvaro Faleiros e eu empurramos a pós. E tivemos apoio, mas um apoio mediano.

O Tradusp começou em agosto de 2012. A pior coisa foi o parecer muito elogioso aqui dentro da faculdade. Quando saiu esse parecer, pensamos "Oh, somos os melhores!", e não nos precavemos contra qualquer tipo de problema que poderíamos ter depois. Na época pensamos "Ótimo, ótimo" e não nos demos conta desses problemas estruturais que acabaram com o programa. Ainda está rolando a tentativa de reverter a nota baixa dada pela Capes. Angela Zucchi e Heloísa Cintrão dedicaram muito tempo a isso. Eu não participei quase nada dessa tentativa, mas Angela e Heloísa, especialmente a Heloísa, dedicaram vários meses, e realmente estão empenhadas em reverter essa nota. Parece que não foi resolvido ainda, mas o Tradusp já era. 
Agora o Tradusp vai se fundir com o novo programa, LETRA (Letras Estrangeiras e Tradução). Foram seis anos desperdiçados, muito trabalho burocrático, e muito tempo que eu e outros podíamos ter dedicado a outras coisas, mas acho que eu nunca teria me tornado Professor Titular sem o Tradusp, que demonstrou aos meus críticos que eu não era somente "turista" na USP. Burocraticamente, esses programas grandes, como o LETRA, são mais funcionais. O Tradusp foi uma tentativa malsucedida. Quase todos os alunos gostaram, mas a CAPES não gostou. Esse foi o problema

Telma: Seu livro Tradução: teoria e prática, atualmente publicado pela Martins Fontes, está entre os mais vendidos da área no Brasil. Tem planos para outras obras na área de tradução ou adaptação?

John: Meu livro sobre Lobato, Um país se faz com tradutores $e$ traduções: a tradução e a adaptação na obra de Monteiro Lobato, sai em 2019 pela Editora Martins Fontes. Reúne vários anos de trabalho sobre os recontos de Dona Benta, como em Peter Pan e D. Quixote das Crianças, onde Lobato insere suas opiniões por meio das contações de histórias da Dona Benta e dos comentários dos picapauzinhos.

Telma: Esse título é muito sugestivo. Além de brincar com o famoso dito de Lobato, "um país se faz com homens e livros", revela o papel fundamental da tradução na vida dele, que foi tradutor e editor de traduções que até hoje influenciam os brasileiros. Mas esse título revela também a importância que você mesmo credita à tradução...

John: Sim, mas acho que esse título é basicamente para chamar a atenção [risos]. Eu estava esperando que saísse em 2018, mas só vai sair o ano que vem, pela Martins Fontes. Eu poderia ter oferecido a outras editoras, mas conheço a Martins Fontes, que é toda certinha. Mas ficou aquela frustração... Entreguei o livro, a editora-chefe leu, gostou e disse "Vamos publicar". Eu estava quase organizando o lançamento, que teria sido em junho ou julho deste ano, aí ela disse "Mas vamos publicar só o ano que vem, porque este ano está difícil". Então o ano que vem espero publicar e fazer o lançamento antes 
do ENTRAD 3 , em João Pessoa, onde com certeza venderia vinte ou trinta livros.

Telma: Gostaria de acrescentar algo, seja em relação à sua obra, carreira, vida, novos planos?

John: Um interesse novo é a representação fotográfica de tradutores e intérpretes. Recentemente dei uma palestra sobre 'A Fotografia Vitoriana' na Semana Vitoriana, e tenho feito apresentações sobre fotografias de intérpretes de línguas indígenas nos Estados Unidos no Século XIX, e na China na mesma época, e de intérpretes indígenas num período mais recente. Há um acervo fascinante no Museu do Índio no Rio, do SPI (Serviço de Proteção aos Índios), o precursor da FUNAI, com várias fotos dos intérpretes do SPI, alguns dos quais acabaram levando flechadas das tribos mais hostis. Estou trabalhando num artigo junto com Helena Barbosa, aluna do Tradusp. Essa área é totalmente inexplorada, parece que é um campo totalmente virgem, onde há muito pano pra manga!

Nos Diários do Darcy Ribeiro, ele sempre reclama dos intérpretes, diz que são preguiçosos, não traduzem tudo, vão embora quando querem... E ele reclama toda hora do SPI. Tem muita coisa aí, que eu acho que ninguém investigou. Claro que muita gente tem trabalhado com lendas indígenas, mas não com a interpretação dos indígenas, que para mim é uma área totalmente diferente. Estou no Brasil há muito tempo, mas nesse tempo eu tive pouco interesse pelos índios... pode-se falar "índio" ainda?

Telma: Acho que sim...

John: Eu levei uma bronca falando Indian em inglês. Darcy Ribeiro fala "índio" o tempo todo, mas isso foi nos anos 1950. O artigo com a Helena é sobre o SPI e uma parte é sobre o Darcy também. Quanto aos intérpretes indígenas, alguns deles, que vieram de fora, eram brancos, empregados do SPI. Outros eram os próprios índios. Uma intérprete muito importante foi a Vanuíre, que pertencia aos grupos indígenas de São Paulo e Paraná. Ela ajudou muito a acalmar os índios, para não atacarem os brancos. É claro que houve, nos assentamentos de São Paulo e Paraná, muitas mortes,

\footnotetext{
${ }^{3}$ Aqui se trata do XIII Encontro Nacional de Tradutores (ENTRAD) e VII Encontro Internacional de Tradutores, a ser realizado de 7 a 11 de outubro de 2019 na Universidade Federal da Paraíba, em João Pessoa
} 
especialmente por doenças como sarampo e caxumba, mas também por brigas. Embora em alguns casos os índios tenham matado os fazendeiros e os jagunços, os brancos sempre dominavam e acabavam tomando as terras, no fim. Então o SPI criou os assentamentos indígenas, um tipo de lugar onde os índios tinham alguma segurança. E claro que uma grande pessoa por trás disso foi o Rondon.

Telma: Você sabe como ela conseguiu isso?

John: Pelo jeito. Ela estava dentro do compound, onde os índios tinham segurança, e quando os índios mais violentos queriam atacar, ela fazia algum tipo de sinal, de canto, para convencê-los a não atacar. Há muitas histórias, e Helena está trabalhando nisso, mas parece que a interpretação nessa área não é só falar. Uma parte são sinais, são cantos, são gritos... que são tão importantes quanto a própria fala. E Helena sempre diz que há uma maneira diferente na própria interpretação dos índios quando eles falam. Então há uma coisa tradicional, entre os índios, de não só traduzir o que foi falado, mas também de acrescentar comentários, como no caso de Megaron, intérprete do seu tio, Raoni. Quando tem interpretação de um falante indígena nos congressos, o intérprete, que em geral é um tipo de amigo de quem está falando, ele não só traduz, mas também explica, acrescentando comentários... Não é aquela coisa de cabine, de se restringir ao que foi dito. Tem muitas coisas fascinantes, que parece que ninguém tocou exatamente ainda.

Telma: E quanto à tradução de poesia? É algo que ainda o motiva? Você traduziu John Keats (Nas invisíveis asas da poesia, Iluminuras, 1989), William Wordsworth ( $O$ olho imóvel pela força da harmonia, Ateliê, 2007), e Percy Shelley (Sementes aladas, Ateliê, 2010) em parceira com Alberto Marsicano. Traduções em parceria pertenceriam mais a um tradutor que ao outro? É correto usar o verbo 'pertencer'? Você acha que o tradutor é um coautor à altura do autor?

John: Sim, quero voltar à tradução de poesia e talvez publicar um volume de traduções de Gregório de Matos em inglês. Nos volumes de traduções de Keats, Wordsworth e Shelley, eu estava ajudando Marsicano. No momento, estou ajudando o aluno de iniciação científica Pedro Mohallem, 
com suas traduções de Tennyson que, por incrível que pareça, é inédito no Brasil! Mas Gregório em inglês seria meu!

Telma: Gregório de Matos é fascinante! Acho que sua resposta enfática "Gregório em inglês seria meu!" dá uma pista do que você pensa sobre a questão da autoria na tradução... Você já tem alguns poemas dele traduzidos que poderia compartilhar?

John: Sim, a Cadernos de Literatura em Tradução 6, de 2005, publicou cinco traduções minhas de poemas dele: "Gregório de Matos - Cinco poemas em inglês"4. Além disso, há muito tempo atrás, quando a gente publicou Modern Poetry in Translation, publicamos um encarte, um fascículo de poesia brasileira, que tinha poemas do Gregório. Foi publicado em Londres, eu organizei o volume junto com Fernando Dantas, meu orientando. Ele já faleceu.

Tem essa parte triste também. Três orientandos meus já faleceram. Glauco, Irene e Fernando. Uma pena... A Irene tinha acabado de entrar na carreira universitária quando o problema de câncer voltou. Ela fez tratamento contra o câncer durante muito tempo, e o doutorado até ajudou ela a superar a doença... Mas depois piorou.

Telma: É muito triste. A Irene foi uma grande parceira sua, vocês fizeram muitas coisas juntos. No Memorial, você fala sobre essas perdas, sobre as parcerias... Você não pensa em publicá-lo?

John: Não, nunca pensei, porque foi uma coisa que fiz para obter a Titulação, e passou. Mas pode ser. Talvez seja uma boa ideia publicá-lo.

\footnotetext{
${ }^{4}$ Leia as traduções aqui: http://www.revistas.usp.br/clt/article/view/49390/53464
} 